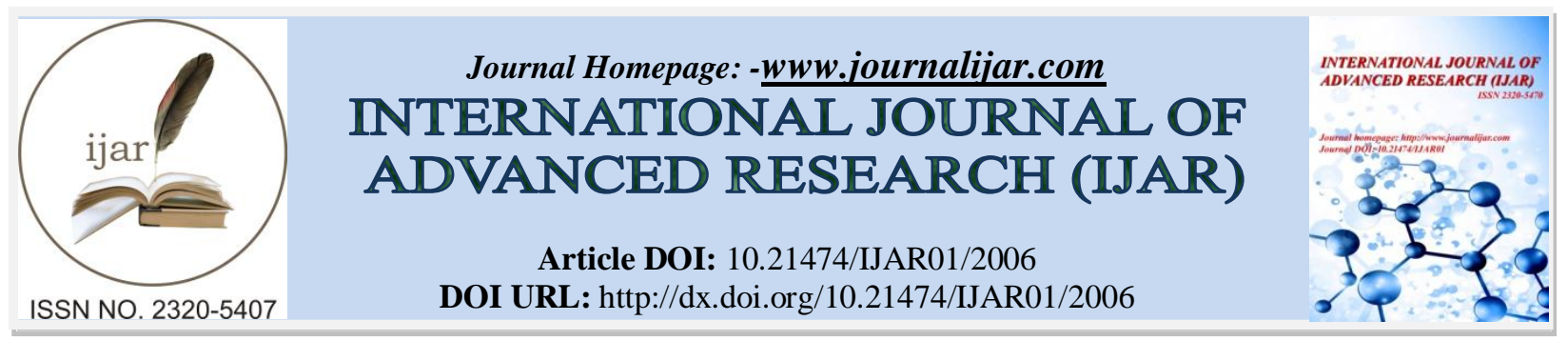

RESEARCH ARTICLE

\title{
EXAMINATION OF THERMO-PHYSICAL PROPERTIES OF ETHANOL AND GASOLINE NUMERICALLY AND ITS BEHAVIOUR AT DIFFERENT TEMPERATURES.
}

Harish Sivasubramanian.

harishsivasubramanian23@gmail.com

Department of Mechanical engineering, Velammal Engineering College.

\section{Manuscript Info}

Manuscript History

Received: 18 September 2016

Final Accepted: 25 October 2016

Published: October 2016

Key words:-

Numerical methods; Ethanol; Thermophysical properties; Cold-start;

Temperature Variation.

\section{Abstract}

Currently, the atmospheric pollution has become a major problem leading to global warming, air-borne diseases etc. In order to find a suitable solution to this problem, the entire world is now switching to the alternatives. The thermo-physical properties vary for the alternatives and in order to use these, it is very essential to study their variation. In this paper, properties of ethanol and gasoline are calculated by mathematical methods and their values and trends are used to predict their behaviour. Ethanol has a problem of cold-start and smoother flow; thus it is essential to study its behaviour throughout its path from fuel tank to the intake manifold. The temperature may vary roughly around 20 to $100^{\circ} \mathrm{C}$ along its path as quoted by some research papers; thus this temperature range was chosen for the study. The viscosity was found to decrease slowly with temperature for ethanol than gasoline indicating poor fluidity. The values for density and thermal conductivity were found to be higher for ethanol when compared to gasoline. In addition to that, the lower specific heat of ethanol indicates its potential to suppress the problems associated with cold-start but only to minimal extent.

Copy Right, IJAR, 2016,. All rights reserved.

\section{Introduction:-}

Nowadays, globally the problem faced is the atmospheric pollution which is caused by the noxious and detrimental gases released into the atmosphere. In order to meet these demands many stringent norms and fuel economy standards that benefit both the environment and people are put forward. The only elucidation to this issue is to shift to the alternate fuels. Though, alternatives have a great potential to mitigate the emissions up to an extent, it limits its usage by a slight decline in its power. There are many important factors to be considered before selecting and commercializing a fuel like heat of vaporization, flash point, viscosity etc. These factors vary with their temperature and hence it is very essential to understand their variation. There are many mathematical formulations used to calculate their values and these values are compared with the actual value. In this paper, the thermo-physical properties of ethanol and gasoline are calculated mathematically to study clearly about its trends. Li et al. [1] had studied the Physio-chemical properties of ethanol-diesel blends by conducting an experiment in water-cooled single cylinder Direct Injection (DI) diesel engine. It was found that the addition of ethanol to diesel lowers the fuel viscosity which leads to injector leakages and its lower energy density had lowered the volumetric efficiency. In addition to that, the distillation curve was also modified with the addition of ethanol due to its lower boiling point. It was observed that the spray quality was improvised due to the lower boiling point of ethanol and its lower flame 
temperature also aided in reduced heat losses. It was also concluded that ethanol remained unstable at lower temperatures and became stable at higher temperatures tolerating water contamination.

Torres et al. [2] focused on properties like density, fuel stability; viscosity, flash point, etc. for ethanol-diesel blended fuels. It was concluded that the additives were not necessary for maintaining stability of ethanol at low temperatures and the pour point and cloud point were found to be improved with ethanol addition. Torres et al. [3] had also presented the obtained fuel properties of tested fuels and their influence on engine characteristics. The fuel was tested with diesel in blend percentages of 5\%, 10\% and 15\%. In this study, he concluded that ethanol required some additives in order to compensate the low temperature instability which was a result contrary to his earlier paper. It was found that the density and viscosity were reduced with ethanol addition and on the other side the lubrication property was also improved. It was stressed out that special care should be taken on ethanol at lower temperatures, as they are hygroscopic in nature. Ajav and Akingbehin [4] also studied some properties like relative density, viscosity, etc. and concluded that the density and viscosity decreased with blends. Hansen et al. [5] have reviewed the ethanol-diesel blends and also concluded that the fuel viscosity decreased with blend which resulted in greater pump and injector leakages. On the other hand, it was also found to cause some problems in hot restart of the engine and also concluded that the fuel viscosities have a crucial role in atomization and spray characteristics. Ghobadian et al. [6] had investigated the fuel blend properties of bioethanol and sunflower methyl ester and found that the low freezing point of ethanol had improved its low-temperature flow properties. It was found that the addition of ethanol had lowered the flash point and also stressed the necessity of being cautious in the storage and transportation of the fuel.

Lapuerta et al. [7] had studied about the properties of alcohol-diesel blends and concluded that lower mass alcohols like ethanol has poor blending stability and viscosity. Ali et al. [8] had studied the improvement of properties with the addition of ethanol and concluded that ethanol blends showed slightly superior behaviour in terms of its density, viscosity, acid value and its low temperature performance. Kwanchareon et al. [9] tested the solubility of dieselbiodiesel and ethanol blends and concluded that the inter-solubility of the components decreased at lower temperatures but phase separation was not found above $20^{\circ} \mathrm{C}$. P. Satge de Caro et al. [10] had concluded that ethanol had good fluidity at lower temperatures and metallic cylinders were not corroded even in the presence of hydrated ethanol. In addition to this, the viscosity values of ethanol were not found to exceed the minimum requirements of diesel engine with blend percentages of 10-20\%. Kheiralla et al. [11] found an increase in the density and viscosity and a decrease in heat value with the addition of ethanol. The flash point was higher for ethanol than pure gasoline and concluded it by saying that the ethanol-gasoline blends can be used up to $35 \%$ without any engine modifications.

This literature review shows the variation of the properties of ethanol blended with gasoline or diesel and some of their effects on the engines. The temperature of the fuel mixture tends to increase as it approaches from the fuel tank to the intake manifold and so it is very essential to study the variation of the thermo-physical properties throughout its path. This helps us in predicting the factors which mainly contribute to the problem associated with cold-start and vapour lock as they implicitly affect the performance and emission in engines. In this study, various thermo-physical properties are calculated numerically for a temperature range of $20-100^{0} \mathrm{C}$ for pure gasoline and pure ethanol are studied.

\section{Properties of Ethanol:-}

There are many factors which contribute to the behaviour of the fuel which include density, vapor pressure, etc. that plays a crucial role in cold-start and vapour lock condition. Some of the general properties [12,13] of ethanol and gasoline are shown in Table 1.

Table 1:- General Properties of Ethanol and Gasoline.

\begin{tabular}{|l|l|l|}
\hline Property & Ethanol & UG \\
\hline Chemical formula & $\mathrm{C}_{2} \mathrm{H}_{5} \mathrm{OH}$ & $\mathrm{C}_{4}-\mathrm{C}_{12}$ \\
\hline Molecular weight $(\mathrm{g} / \mathrm{mol})$ & 46.07 & $100-105$ \\
\hline Density $\left(\mathrm{kg} / \mathrm{m}^{3}\right) @ 15^{0} \mathrm{C}$ & 790 & $690-790$ \\
\hline Boiling point $\left({ }^{0} \mathrm{C}\right)$ & 78.8 & $27-225$ \\
\hline Critical Temperature $\left({ }^{0} \mathrm{C}\right)$ & 240.9 & 295.7 \\
\hline Critical Pressure (bar) & 61.48 & 24.9 \\
\hline
\end{tabular}




\begin{tabular}{|l|l|l|}
\hline Flash point $\left({ }^{\circ} \mathrm{C}\right)$ & 11.75 & -12 \\
\hline Lower Heat Limit (\% volume of air) & 4.3 & 1.4 \\
\hline Upper Heat limit (\% volume of air) & 19 & 7.6 \\
\hline Carbon Content (mass per cent) & 52.2 & $85-88$ \\
\hline Hydrogen Content (mass per cent) & 13.1 & $12-15$ \\
\hline Oxygen Content (mass per cent) & 34.7 & 0 \\
\hline Heat of Vaporization $(\mathrm{Kj} / \mathrm{Kg})$ & 921.096 & 348.9 \\
\hline Specific Heat $(\mathrm{J} / \mathrm{g}-\mathrm{K}) @ 25^{\circ} \mathrm{C}$ & 2.44 & 2.22 \\
\hline Thermal Conductivity $(\mathrm{W} / \mathrm{m}-\mathrm{K}) @ 25^{\circ} \mathrm{C}$ & 0.17 & 0.15 \\
\hline
\end{tabular}

\section{Methods and Calculations:-}

The temperature dependent properties of ethanol are calculated using the numerical methods

Viscosity:-

Viscosity is one of the most important intrinsic properties which are used to analyse the flow of fluids [17]. It is calculated at different temperatures as it is a function of temperature. As the fuel travels from the fuel tank to the intake manifold, the temperature of the fluid rises and becomes nearly equal to $100^{\circ} \mathrm{C}$ near the intake manifold [15][16] and thus these temperature ranges were chosen. The calculations were carried out using a method postulated by Sastri[14] which is given by,

where, $\eta$ is the viscosity in mPa.s

$$
\begin{gathered}
\ln \eta=\left[\frac{\ln \eta_{B}}{\ln \left(\alpha \eta_{B}\right)}\right]^{\phi}\left(\ln \left(\alpha \eta_{B}\right)\right) \\
\phi=\left[\frac{1-T_{r}}{1-T_{b r}}\right] \\
T_{r}=\frac{T}{T_{c}} \\
T_{b r}=\frac{T_{b}}{T_{c}}
\end{gathered}
$$

$\eta_{B}$ is the viscosity at $\mathrm{T}_{\mathrm{B}}$ in $\mathrm{mPa}$.s

$\alpha$ is 0.1175 for alcohols, 0.248 for Gasoline

$T_{r}$ is reduced temperature in Kelvin

$T_{b r}$ is the reduced boiling temperature in Kelvin

Table 2:- Values of $\Delta \eta_{B}$.

\begin{tabular}{|l|l|l|l|}
\hline Groups & \multicolumn{1}{|c|}{$\boldsymbol{N}_{\text {Ethanol }}$} & \multicolumn{1}{c|}{$\boldsymbol{N}_{\text {Gasoline }}$} & \multicolumn{1}{c|}{$\boldsymbol{\Delta} \boldsymbol{\eta}_{\boldsymbol{B}}$} \\
\hline $\mathrm{CH}_{3}$ & 1 & 2 & 0.105 \\
\hline $\mathrm{CH}_{2}$ & 1 & 6 & 0 \\
\hline $\mathrm{OH}$ & 1 & 0 & $0.615-0.092 C+0.004 C^{2}$ \\
& & & $-10^{-0.58 C}$ \\
\hline
\end{tabular}

Here $\mathrm{C}$ is the no of carbon atoms in ethanol which is 2 and Table 2 shows the values for number of molecules for gasoline and ethanol [14]. The value of $\eta_{B}=N_{C_{3}}+N_{C_{2}}+N_{O H}$ and here $\mathrm{N}$ represents the number of molecules. The value obtained by this calculation is $0.00133 \mathrm{~Pa}$-s for ethanol whereas the actual value is $0.0012 \mathrm{~Pa}-\mathrm{s}$ which has a percentage deviation of $10.83 \%$. Similarly all the values are calculated for different temperatures and plotted in the form of a graph.

\section{Density:-}

The density of the substance is defined as the mass present in its unit volume. Whenever heat is extracted from a fluid, the fluid will become compact as the particles slow down and come closer to each other. This will decrease the volume as it is compacted. As the volume decreases, the density of the substance starts to increase. So the fluid has a higher density at colder temperature and the opposite effect is observed at higher temperatures. It is evident that ethanol has greater density than gasoline and so there will be fewer problems associated with vapour lock and more problems associated with cold-start in ethanol. The values of density are calculated using Equation 5 formulated by Elbro et al.[14], 


$$
\begin{gathered}
\rho=\frac{M}{V} \\
V=\sum_{i} n_{i} \Delta \mathrm{v}_{i} \\
\Delta \mathrm{v}_{i}=A_{i}+B_{i} T+C_{i} T^{2}
\end{gathered}
$$

Table 3:- Values of $A, B$ and $C$.

\begin{tabular}{|l|l|l|l|l|l|}
\hline GROUPS & \multicolumn{1}{|c|}{$\boldsymbol{n}_{\boldsymbol{i}(\text { Ethanol })}$} & \multicolumn{1}{c|}{$\boldsymbol{A}$} & \multicolumn{1}{c|}{$\boldsymbol{B} * \mathbf{1 0}^{\mathbf{3}}$ (Gasoline) } & \multicolumn{1}{c|}{$\boldsymbol{C} * \mathbf{1 0}^{\mathbf{5}}$} \\
\hline $\mathrm{CH}_{3}$ & 1 & 2 & 18.960 & 45.58 & 0 \\
\hline $\mathrm{CH}_{2}$ & 0 & 6 & 12.52 & 12.94 & 0 \\
\hline $\mathrm{CH}_{2} \mathrm{OH}$ & 1 & 0 & 39.460 & -110.60 & 23.31 \\
\hline
\end{tabular}

The value calculated at $300.48 \mathrm{~K}$ is found to be $0.7815 \mathrm{~g} / \mathrm{cm}^{3}$ and the actual value was found to be $0.7687 \mathrm{~g} / \mathrm{cm}^{3}$. The percentage deviation between the calculated and actual value was found to be $1.66 \%$.

\section{Thermal Conductivity:-}

Thermal conductivity is the property of the material to conduct heat. It is known that when the thermal conductivity is lower, then the heat transfer rate is also slow. The thermal conductivity of a liquid or any substance varies with its temperature and so in this present study, the thermal conductivities of the liquids at different temperatures are calculated. The equation for calculating the thermal conductivity is given by Latini et al. method [14][18].

$$
\begin{gathered}
\lambda_{L}=A\left[\frac{\left(1-T_{r}\right)^{0.38}}{\left(T_{r}\right)^{\frac{1}{6}}}\right] \\
A=\left[\frac{A^{*} T_{b}{ }^{\alpha}}{M^{\beta} * T_{c}{ }^{\gamma}}\right]
\end{gathered}
$$

where, $\lambda_{L}$ is the thermal conductivity of the liquid in $\mathrm{W} / \mathrm{m}-\mathrm{K}$.

$M$ is the Molecular weight in $\mathrm{g} / \mathrm{mol}$.

$T_{b}$ is the boiling temperature in Kelvin.

$T_{c}$ is the Critical temperature in Kelvin.

For alcohols, $A^{*}=0.00339 ; \alpha=1.2 ; \beta=0.5 ; \gamma=0.167$.

For gasoline, $A^{*}=0.0035 ; \alpha=1.2 ; \beta=0.5 ; \gamma=0.167$.

The actual value of thermal conductivity is $0.166 \mathrm{~W} / \mathrm{m}-\mathrm{K}$ and calculated value at $300 \mathrm{~K}$ is $0.1566 \mathrm{~W} / \mathrm{m}-\mathrm{K}$ resulting in a percentage deviation of $-5.66 \%$ between the actual and calculated value.

\section{Specific Heat:-}

Specific heat is the amount of heat required to raise the temperature of unit mass of a substance by $1^{0} \mathrm{C}$. At colder temperature near the fuel tank, the fluid molecules will remain in their ground state and do not contribute to their total thermal energy. As the temperature increases, the molecules start to translate, rotate and reach higher energy states. As this rotation begins, it will contribute to the internal energy and raises the molar specific heat. The liquid heat capacities can be calculated using the method of Ruzicka and Domalski [14] and it is given by Equation 16,

$$
\begin{gathered}
C_{P L}=R\left[A+B\left(\frac{T}{100}\right)+D\left(\frac{T}{100}\right)^{2}\right] \\
A=\sum_{i=1}^{k} n_{i} a_{i} \\
B=\sum_{i=1}^{k} n_{i} b_{i} \\
D=\sum_{i=1}^{k} n_{i} d_{i}
\end{gathered}
$$

where, $\quad C_{P L}$ is the specific heat at constant pressure in $\mathrm{J} / \mathrm{mol} \mathrm{K}$ 
$\mathrm{R}$ is the universal gas constant in $\mathrm{J} / \mathrm{mol} \mathrm{K}$

$\mathrm{T}$ is the temperature in Kelvin

Table 4:- Values of Constants $a, b$ and $d$.

\begin{tabular}{|l|l|l|l|l|l|l|}
\hline Group & $\mathbf{n}_{\text {ethanol }}$ & $\mathbf{n}_{\text {gasoline }}$ & $\mathbf{a}$ & $\mathbf{b}$ & $\mathbf{d}$ & Ref. \\
\hline $\mathrm{CH}_{3}$ & 1 & 2 & 3.8452 & -0.339 & 0.19489 & 14 \\
\hline $\mathrm{CH}_{2}$ & 1 & 6 & 2.797 & -0.0549 & 0.1067 & 14 \\
\hline $\mathrm{OH}$ & 1 & 0 & 12.952 & -10.145 & 2.6261 & 14 \\
\hline
\end{tabular}

By substituting the values from Table 4 in Equations 11, 12 and 13, we get $\mathrm{A}=19.5942 ; \mathrm{B}=-10.538 ; \mathrm{D}=2.9276$ for ethanol and $\mathrm{A}=24.47 ; \mathrm{B}=-1.007 ; \mathrm{D}=1.029$ for gasoline. These values are substituted in Equation 16 to obtain the required values. The value obtained by calculation for ethanol is $117.96 \mathrm{~J} / \mathrm{mol} \mathrm{K}$ whereas the actual value is 115.9 $\mathrm{J} / \mathrm{mol} \mathrm{K}$ at $298 \mathrm{~K}$ and hence the percentage deviation in this method is $1.7 \%$.

\section{Results and Discussion:-}

Viscosity:-

Fig 1 shows that as the temperature is increased, the viscosity gets decreased. This shows that as the fluid approaches the intake manifold, the tightness in the fluid is lost as the molecules are separated and the particles are able to move past each other. The trend witnessed in the figure shows that the viscosity increases in ethanol. This indicates that though the tightness is decreased by higher temperatures, the fluid flow property of gasoline is more compared to ethanol as higher viscosity of ethanol affect its smoother flow. Thus there would be minimal flow hindrance in case of gasoline while flowing from the fuel tank. In addition to that, the slope of the curve for ethanol is less than one indicating that more amount of temperature rise is required for a considerable decreased in viscosity.

\section{Temperature Vs Viscosity}

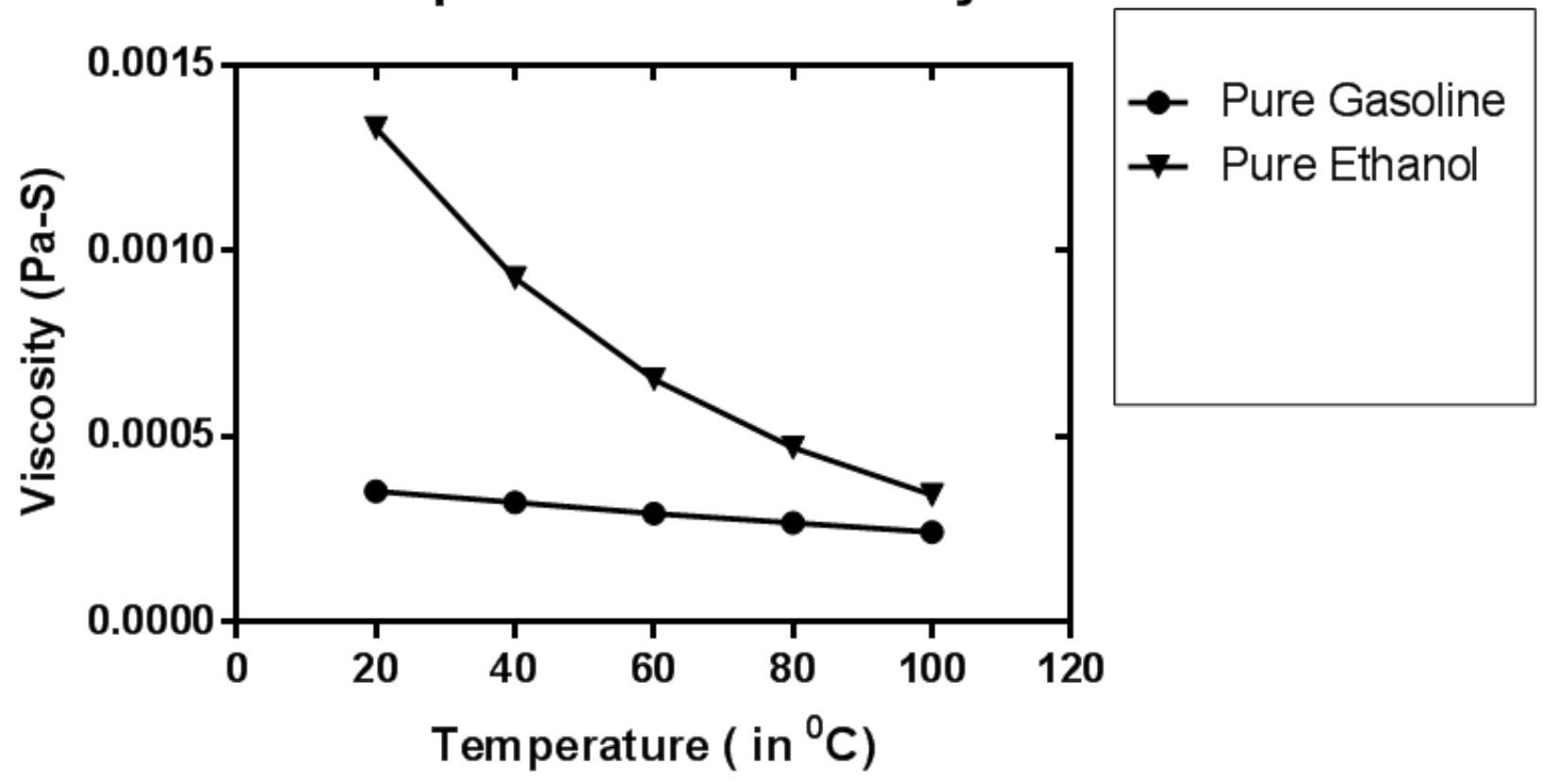

Density:-

Fig 1:- Temperature Vs Viscosity.

Fig 2 shows a graph between the density and temperature for pure gasoline and pure ethanol. It is evident from the graph, as temperature increases, the density decreases. Thus the fluid will almost get converted to vapour before entering the cylinder and there will be an increase in the kinetic energy of the molecules which increases the flow. In addition to this, the higher density of ethanol increases the float level supplying a rich mixture into the cylinder which reduces the $\mathrm{CO}$ and $\mathrm{HC}$ emissions improving the combustion quality [19]. On the other hand, there might also be problems in vaporizing the fuel in case of pure ethanol as its density is higher than gasoline as shown in Fig 2. 


\section{Temperature Vs Density}

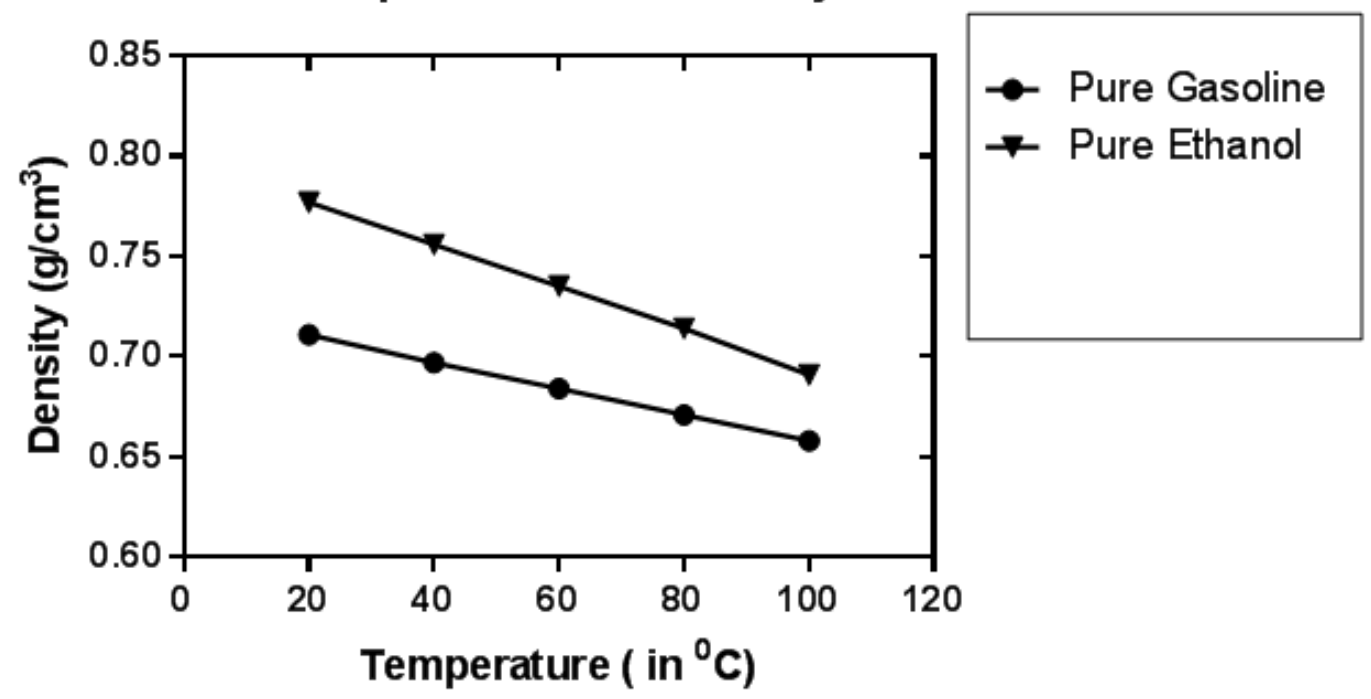

Fig 2:- Temperature Vs Density.

\section{Thermal Conductivity:-}

It is evident from Fig 3 that the thermal conductivity decreases with temperature which resembles the trend obtained by Mohan et al. [18]. The thermal conductivity of the fuel near the fuel tank would be high and it gradually decreases along its path to the intake manifold. So it depicts the fact that the amount of heat loss decreases near the intake manifold because of the lower thermal conductivity near it. Among these fuels, the thermal conductivity of ethanol is higher than gasoline which shows that more amount of heat is conducted in ethanol resulting in higher heat loss. Thus air-fuel mixture in the intake manifold will be at a higher temperature for gasoline than ethanol. The fuel should absorb more amount of heat instead of losing to avoid cold-start problems and improve Brake thermal Efficiency (BTE). On the other hand, the higher thermal conductivity of ethanol would cool down the surrounding components helping them to relieve from thermal stresses to a certain extent.

\section{Temperature Vs Thermal Conductivity}

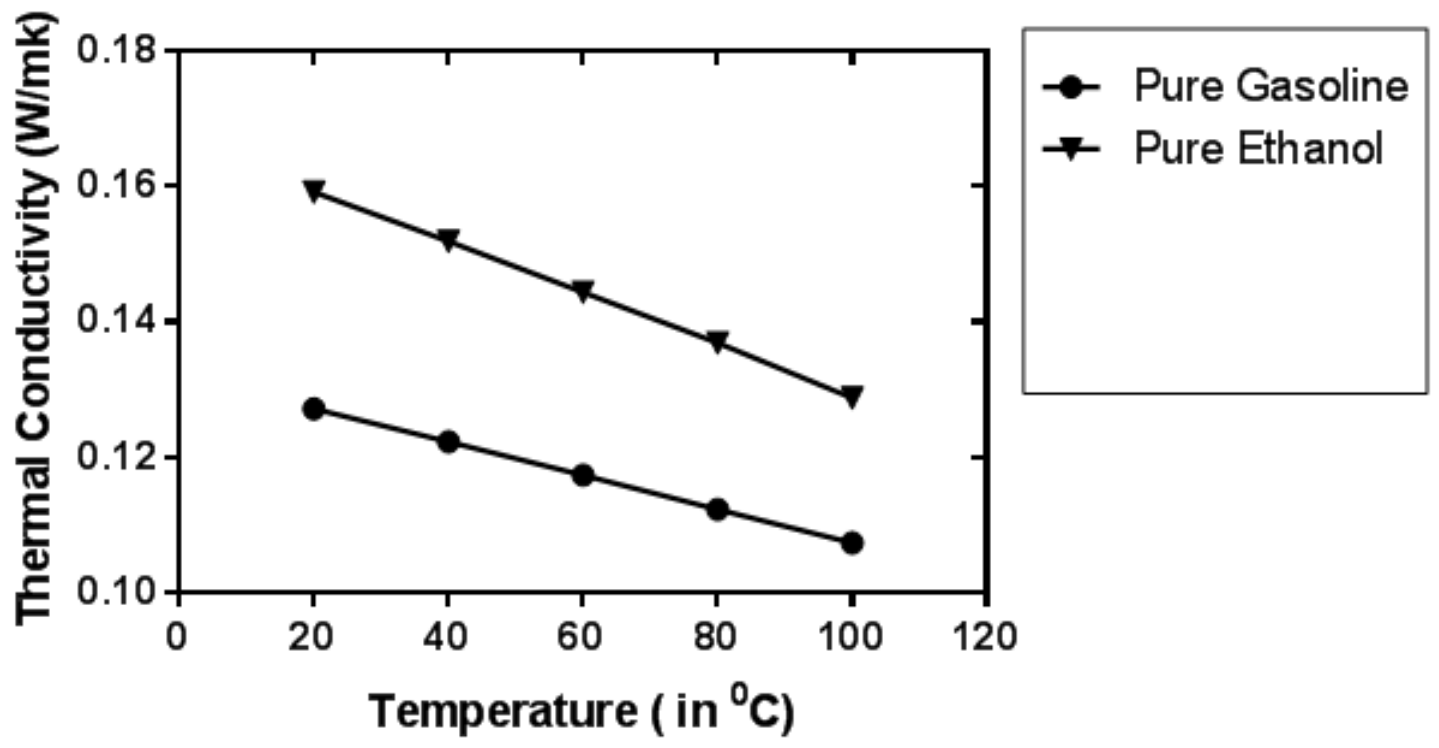

Fig 3:- Temperature Vs Thermal conductivity. 


\section{Specific heat:-}

Fig 4 shows the variation of specific heat with temperature and it is evident that as the temperature increases, the specific heat also increases and attains a higher value near the intake manifold. It is seen that ethanol has a lower specific heat as compared to gasoline which depicts the fact that less amount of heat is required to excite the molecules of ethanol to higher energy states. The hydrogen bonding in gasoline is stronger than ethanol; thus requiring more heat to break down the bond. This may seem to have solved the problems associated with cold-start and poor fluidity but only to a minimal extent that is negligible.

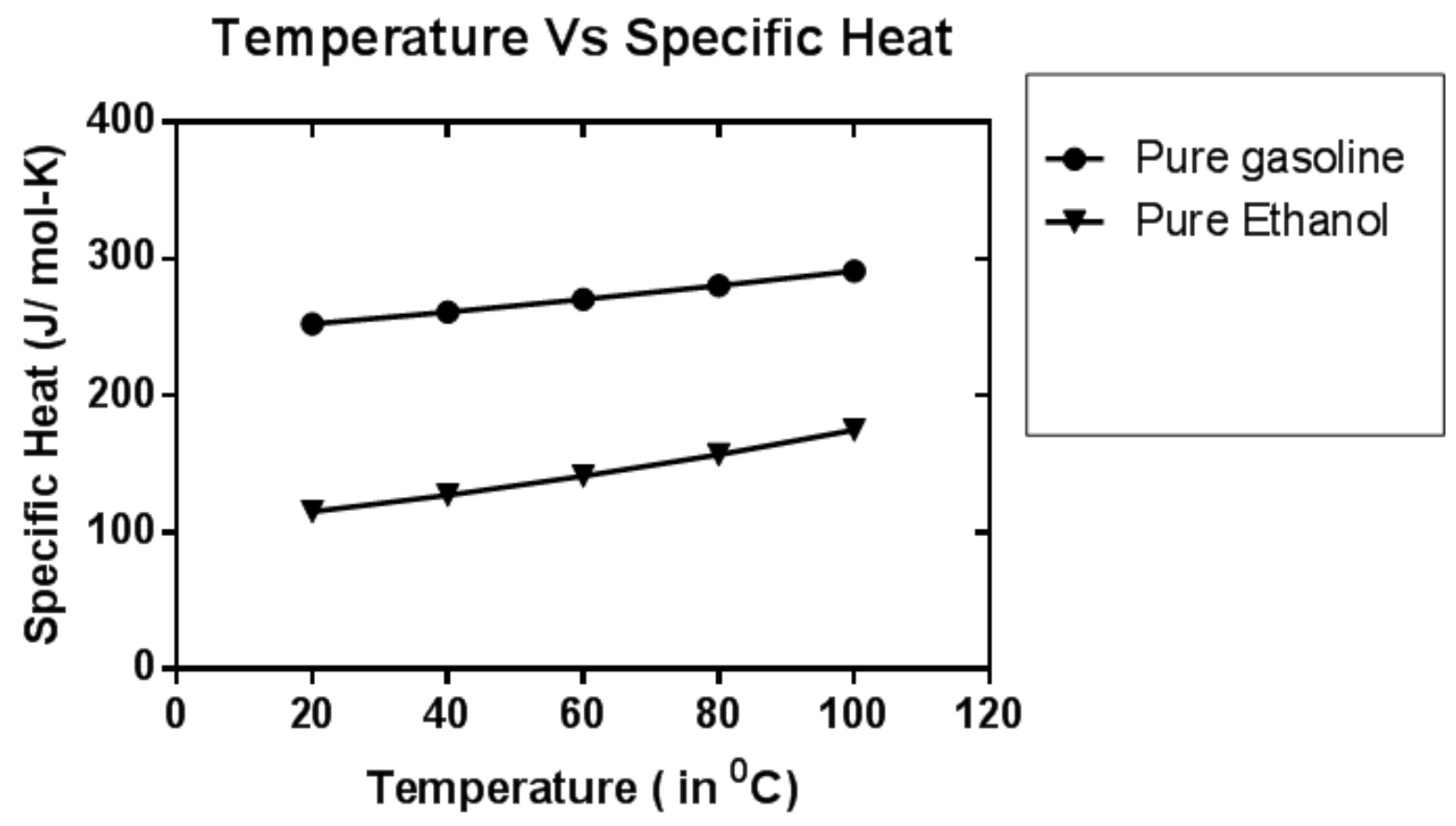

\section{Conclusion:-}

Fig 4:- Temperature Vs Specific Heat

The thermo-physical properties of ethanol and gasoline were calculated numerically and the various temperature dependent properties were calculated at different temperatures. These properties are calculated for a temperature range of $20-100^{\circ} \mathrm{C}$ as the temperature of the fuel from the fuel tank to intake manifold varies in this range. The results indicate that for ethanol, the value of viscosity decreases slowly with temperature than gasoline because of its lower slope value indicating a possibility of flow hindrance in case of ethanol. Thus a preheating method should be adopted for ethanol to ensure smoother flow. The higher density of ethanol at lower temperatures ensures more amount of fuel is injected into the cylinder by lifting the float level.

The higher thermal conductivity of ethanol relieves the thermal stress associated with the components and increases its life. Moreover, the lower specific heat of ethanol has solved the problems associated with cold-start to minimal extent. This stresses out the need to use ethanol in a modified engine with fuel preheaters and also indicates that ethanol can be used in an unmodified engine only in the form of blends. The present method introduced here is also crucial for the further investigation, for calculating the same thermo-physical properties for the blends by using suitable methods and deciding which blend percentage suites the engine by completely eliminating the cold-start problems and flow hindrance. 


\section{References:-}

1. Li D, Huang Z, Lu XC, Zhang W, Yang J. Physico-chemical properties of ethanol-diesel blend fuel and its effect on performance and emissions of diesel engines. Renew Energy 2005;30:967-76. doi:10.1016/j.renene.2004.07.010.

2. TORRES-JIMENEZ E, SVOLJSAK-JERMAN M, GREGORC A, LISEC I, DORADO MP, KEGL B. Physical and Chemical Properties of Ethanol-Biodiesel Blends for Diesel Engines. Energy \& Fuels n.d.;24:2002-9.

3. Torres-Jimenez E, Jerman MS, Gregorc A, Lisec I, Dorado MP, Kegl B. Physical and chemical properties of ethanol-diesel fuel blends. Fuel 2011;90:795-802. doi:10.1016/j.fuel.2010.09.045.

4. AJav E a, Akingbehin O a. A study of some fuel properties of local ethanol blended with diesel fuel. J Sci Res Dev 2002;IV:1-9.

5. Hansen AC, Zhang Q, Lyne PWL. Ethanol-diesel fuel blends - A review. BioresourTechnol 2005;96:277-85. doi:10.1016/j.biortech.2004.04.007.

6. Ghobadian B, Rahimi H, TavakkoliHashjin T, Khatamifar M. Production of bioethanol and sunflower methyl ester and investigation of fuel blend properties. J AgricSciTechnol 2008;10:225-32.

7. Lapuerta M, García-Contreras R, Campos-Fernández J, Dorado MP. Stability, lubricity, viscosity, and coldflow properties of alcohol-diesel blends. Energy and Fuels 2010;24:4497-502. doi:10.1021/ef100498u.

8. Ali OM, Mamat R, Faizal CKM. Improvement of Blended Biodiesel Fuel Properties with Ethanol Additive.Int J AdvSciTechnol 2013;55:21-32.

9. Kwanchareon P, Luengnaruemitchai A, Jai-In S. Solubility of a diesel-biodiesel-ethanol blend, its fuel properties, and its emission characteristics from diesel engine. Fuel 2007;86:1053-61. doi:10.1016/j.fuel.2006.09.034.

10. Satgé De Caro P, Mouloungui Z, Vaitilingom G, Berge JC. Interest of combining an additive with dieselethanol blends for use in diesel engines. Fuel 2001;80:565-74. doi:10.1016/S0016-2361(00)00117-4.

11. Kheiralla AF, El-awad M, Hassan MY, Hussen MA, Osman HI. Effect of Ethanol / Gasoline Blends on Fuel Properties Characteristics of Spark Ignition Engines Effect of Ethanol - Gasoline Blends on Fuel Properties Characteristics of Spark Ignition Engines 2011.

12. Yüksel F, Yüksel B. The use of ethanol-gasoline blend as a fuel in an SI engine. Renew Energy 2004;29:118191. doi:10.1016/j.renene.2003.11.012.

13. Physical U. Using Physical and Chemical Properties to Manage Flammable Liquid Hazards Part 1-B : Physical \& Chemical Properties of Selected Fuels SECTION 1: GENERAL INFORMATION Using Physical and Chemical Properties to Manage Flammable Liquid Hazards Part 1-B : Phys 1966:1-10.

14. Poling BE, Prausnitz JM, O’Connell JP. Properties of Gases and Liquids. 2007. doi:10.1036/0070116822.

15. Holmgren A. Mean Value Modelling of the intake manifold temperature 2005.

16. Johansson T, Johansson B, Tunest P, Aulin H. The Effect of Intake Temperature in a Turbocharged Multi Cylinder Engine operating in HCCI mode. SAE Tech Pap 2009:2009-24 - 0060. doi:10.4271/2009-24-0060.

17. Non. The concept of viscosity.Lect Notes 2010:22-32.

18. Mohan B, Yang W, Yu W, Tay KL. Numerical analysis of spray characteristics of dimethyl ether and diethyl ether fuel.Appl Energy 2016:1-8. doi:10.1016/j.apenergy.2016.01.128.

19. Elfasakhany A. Experimental investigation on SI engine using gasoline and a hybrid iso-butanol/gasoline fuel. Energy Convers Manag 2015;95:398-405. doi:10.1016/j.enconman.2015.02.022. 